\title{
Pterygia are indicators of an increased risk of developing cutaneous melanomas
}

\author{
Julie M Crewe, ${ }^{1}$ Tim Threlfall, ${ }^{2}$ Antony Clark, ${ }^{1}$ Paul G Sanfilippo, ${ }^{3}$ David A Mackey ${ }^{1}$
}

${ }^{1}$ Lions Eye Institute, Centre for Ophthalmology and Vision Science, University of Western Australia, Nedlands, Australia ${ }^{2}$ Department of Health, Western Australian Cancer Registry, Western Australia, Australia ${ }^{3}$ Centre for Eye Research Australia, University of Melbourne, Royal Victorian Eye and Ear Hospital, Melbourne, Australia

\section{Correspondence to} Julie M Crewe, Lions Eye Institute, 2 Verdun Street, Nedlands, Perth, Western Australia 6148; juliecrewe@ lei.org.au

Received 2 May 2017 Revised 4 July 2017 Accepted 7 July 2017 Published Online First 26 August 2017
Check for updates

To cite: Crewe JM, Threlfall T, Clark A, et al. Br J Ophthalmol 2018;102:496-501.

\section{ABSTRACT}

Aim To investigate whether pterygium is an indicator of an increased risk of cutaneous melanoma (CM).

Methods A matched-cohort study, using linked health administrative data sets to identify all hospital-treated pterygium in Western Australia (WA) between 1979 and 2014. We identified pterygium cases from hospital diagnosis and/or procedure International Classification of Diseases 9th revision (ICD-9) and 10th revision (ICD-10) codes and matched cases by age, sex and residential postcode to WA Electoral Roll controls with no known history of pterygium. Both cohorts were linked to the WA Cancer Registry and the WA Deaths Registry.

Results 23625 people had pterygium treatment (64\% male) in WA hospitals. The median age for pterygium diagnosis and/or treatment was 49 years (range 14-96). There were significantly more CM cases in the pterygium cohort compared with the control cohort (1083 vs $874 ; p<0.001)$. In a logistic regression analysis, there was a $24 \%$ increase in the odds of developing a CM in the pterygium cohort, compared with controls, after controlling for other predictors (OR 1.24, 95\% Cl 1.1 to 1.4). The incident rate ratio (IRR) of a malignant CM diagnosis was $20 \%$ greater in people who had treatment for a pterygium compared with controls (IRR 1.2, 95\% Cl 1.0 to 1.4 ).

Conclusion The presence of a pterygium indicates a significantly increased risk of developing a CM. Eye care providers who see patients with developing pterygia should advise these patients of this increased risk and recommend regular skin surveillance.

\section{INTRODUCTION}

Generally, earlier cancer detection leads to better health outcomes and improved patient survival. ${ }^{12}$ In this study, we investigated whether ocular pterygium is an indicator of increased risk of cutaneous melanoma (CM) and could therefore assist in early detection.

Pterygia are ocular surface lesions characterised by elastotic degeneration and fibrovascular proliferation of the limbal conjunctiva. They can affect vision by inducing astigmatism or obstructing the visual axis. The pathogenesis of pterygia has been linked to solar ultraviolet radiation (UVR) exposure in several studies in Australia. ${ }^{3-5}$

Pterygia are common in young to middleaged adults resident in Western Australia (WA), with the highest risk in those who engage in outdoor activities. ${ }^{6-8}$ Similarly, CMs are common in people with a family or genetic history of CM and in those exposed to UVR. Factors that affect CM survival include regular surveillance ${ }^{9}$ and the stage at detection, with the proportion of survivors decreasing with the higher initial stages of the disease. ${ }^{1011}$ The incidence of CM has continued rising over the past 30 years in all countries, and in Australia, ${ }^{12}$ the age-standardised incidence of CMs has almost doubled, from 27 per 100000 to 49 per 100000 per year. ${ }^{13}$ Approximately $15 \%$ of CMs are fatal, and this has remained unchanged over the same period in all populations. ${ }^{14}$

The International Agency for Research on Cancer ${ }^{15}$ recently determined that solar UVR exposure causes cutaneous malignant melanoma (MM). This link is complex, and the degree and extent of solar UVR exposure have significant public health implications in Australia, where it has been estimated that $22 \%$ of the working population currently receive high levels of solar radiation while at work. ${ }^{16}$

This study used the power of whole population health data sets to determine whether the development of a pterygium is an indicator of an increased likelihood of developing either a malignant or an in situ CM.

\section{METHODS}

This matched cohort study used whole-population linked health data sets extracted from WA hospital admissions or the Hospital Morbidity Data Collection (HMDC), the WA Cancer Registry and the WA Deaths Registry.

Pterygium cases were identified from diagnosis and procedure codes in HMDC for the period 1979 to the end of 2014. Cases were identified using the International Classification of Diseases codes (ICD): ICD-9 and ICD-10-AM for either the principal diagnosis or any additional diagnosis of pterygium (372.40-45, H11.0) and/or a principal or additional procedure code for pterygium excision $(11.31,11.32,11.33,11.39$ and 42686-00, 42800-00). All patients diagnosed or treated in a public or private hospital in WA between 1979 and 2014 were cases. Each case was assigned an index date that corresponded to the hospital admission date of their first pterygium diagnosis or treatment (figure 1).

Controls were a 1:1 age ( \pm 2 years), gender and postcode-matched cohort randomly selected from the WA Electoral Roll. Because voting is compulsory for all Australian citizens, the Electoral Roll is considered representative of the adult population. Each control was assigned the same index date as his/her matched case. However, as the state Electoral Roll was not accessible prior to 1988 , any controls required for index dates between 1979 and 1987 were identified from patients in the 
HMDC. These controls were identified from hospital inpatients with a date of birth \pm 2 years of the matched cases, with a hospital separation date \pm 6 months of the case index date and with an HMDC primary diagnosis code or procedure code (ICD-9) for either: otitis externa, otitis media, varicose veins, haemorrhoids, upper respiratory tract infections, deflected septum, nasal polyps, impacted tooth, other dental codes, dislocations, sprains, superficial injuries, contusions, carpel tunnel syndrome or ingrowing nails and no history of pterygium.

Cases and controls were linked to the WA Deaths Registry and to the WA Cancer Registry to identify any individuals with a confirmed CM diagnosis.

The WA Cancer Registry was established in 1982, and analysis in this study was restricted to those individuals with any CM, MM or in situ (CACODE3: MEL) and/or ICD-9 codes: 172.0-9, or ICD-10 codes: C43.0-C43.9 (MM of skin), 173 .n, or C44.0-C44.9 (other malignant neoplasms of skin), $232 . n$, D03.0-D03.9 (melanoma in situ) and D04.0-D04.9 (carcinoma in situ of skin). We did not include data on basal cell carcinomas or squamous cell carcinomas here as neither were routinely reported to the WA Cancer Registry.

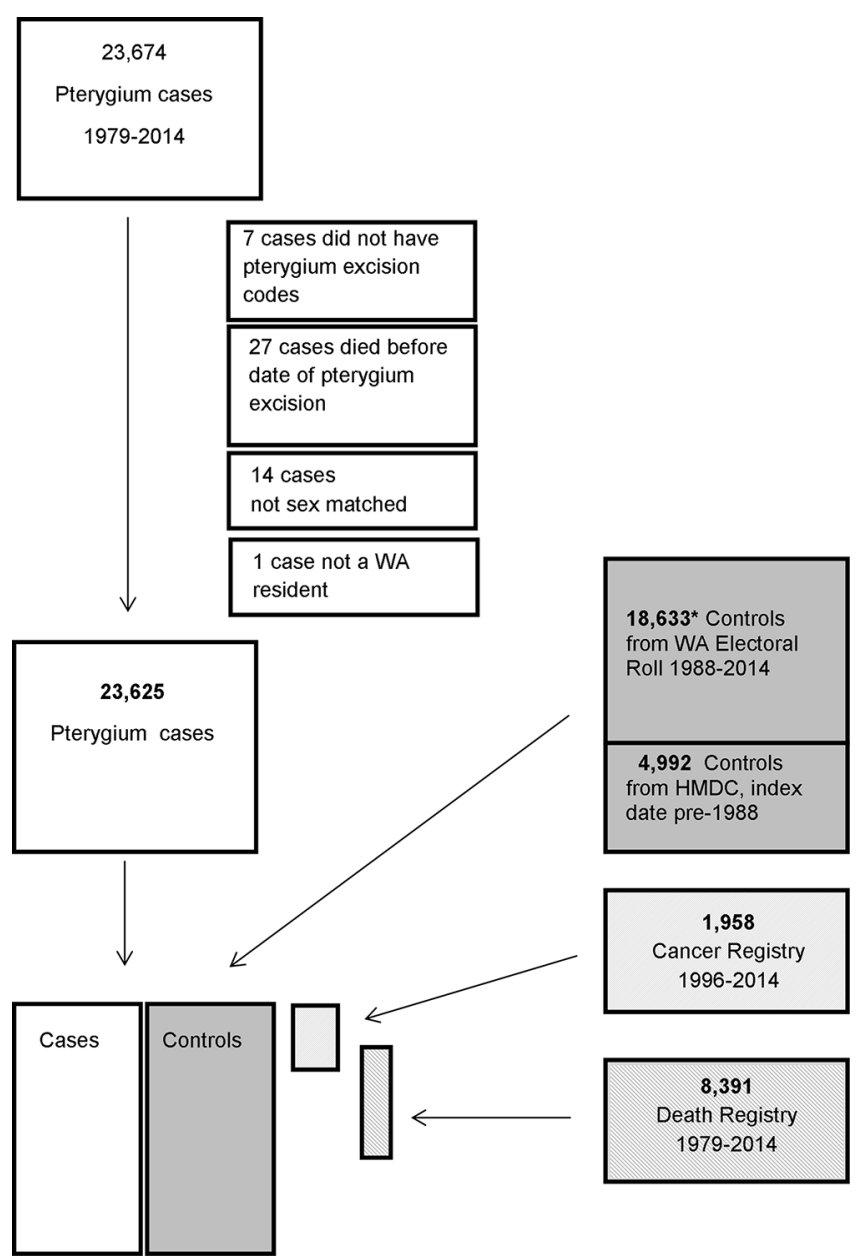

Figure 1 Flow chart of pterygium cases and controls. *784 controls had missing dates of birth (MM/YYYY) but were age matched to a pterygium case with a date of birth. These were presumed to be individuals with no hospital, cancer or death records but present on the WA Electoral Roll. HMDC, Hospital Morbidity Data Collection.
The selection of controls from the state Electoral Roll, the extraction of hospital morbidity data and the linkage to cancer and death registration records was performed by the Data Linkage Branch in the Department of Health Western Australia.

Residential postcodes were used to describe latitude and geographical area as either: within the Perth metro area (postcodes 6000-6199), rural/remote (neither metropolitan nor tropical regions of WA) (postcodes 6200-6699) or tropical (north of the Tropic of Capricorn) (postcodes 6700-6799).

\section{Statistical analysis}

Bivariate associations between demographic factors and pterygium treatment were tested using Pearson's $\chi^{2}$ test for categorical variables, $t$ tests for normally distributed continuous variables and the Wilcoxon rank-sum test for medians. The CM status of matched pairs was compared using a McNemar test. The association between pterygium and CM diagnosis was further investigated using logistic regression modeling adjusted for sex, age at the index date and residential postcode (urban, rural or tropical).

Not all people were followed for the same length of time over the 35 years of the study, for a variety of reasons, including death and therefore the opportunity for developing a CM varied. For cases and controls, the number of CM occurring was expressed as an incidence rate. The mean number of CMs per person-years (PY) of follow-up was calculated.

Analysis was carried out using IBM PASW (SSPS) software V.23 and the R statistical software (R Development Core Team 2016).

This study was approved by the Human Research Ethics Committee of the University of Western Australia (RA/4/1/6878) and the Department of Health WA (\#2014/62), and the research adhered to the tenets of the Declaration of Helsinki.

\section{RESULTS}

There were 23625 people admitted to WA hospitals with a diagnosis or treatment code for pterygium (64\% male) between 1979 and 2014 (table 1). Pterygium treated each year peaked at 56 per 100000 in $1981(\mathrm{n}=736)$ and declined over the following 7 years to a low of 19 per 100000 in $1988(n=290)$. Thereafter, hospital diagnoses/treatment for pterygium have remained

\begin{tabular}{|c|c|c|c|}
\hline & Pterygium cases & Controls & $\mathrm{p}$ \\
\hline \multicolumn{4}{|l|}{$\operatorname{Sex}(n(\%))$} \\
\hline Female & $8440(36)$ & $8440(36)$ & \\
\hline Male & $15185(64)$ & $15185(64)$ & \\
\hline Total & $23625(100)$ & $23625(100)$ & \\
\hline \multicolumn{4}{|c|}{ Age at the Index date $(\mathrm{n}(\%))$} \\
\hline$<50$ years & $11603(49)$ & $11574(49)$ & \\
\hline$\geq 50$ years & $12022(51)$ & $12051(51)$ & \\
\hline Mean (SD) & $50( \pm 16)$ & $50( \pm 16)$ & \\
\hline \multicolumn{4}{|l|}{ Residence (n (\%)) } \\
\hline Urban & $16384(69)$ & $16213(68)$ & \\
\hline Rural or remote & $6316(27)$ & $6530(28)$ & \\
\hline Tropical & $925(4)$ & $882(4)$ & \\
\hline Deaths (n (\%)) & $3653(15)$ & $4269(18)$ & $<0.001$ \\
\hline \multicolumn{4}{|c|}{ Cutaneous melanoma ( $\mathrm{n}(\%))$} \\
\hline Malignant & $646(2.7)$ & $530(2.2)$ & $<0.001$ \\
\hline In situ & $437(1.8)$ & $344(1.5)$ & $<0.001$ \\
\hline Total & $1083(4.6)$ & $874(3.7)$ & $<0.001$ \\
\hline
\end{tabular}




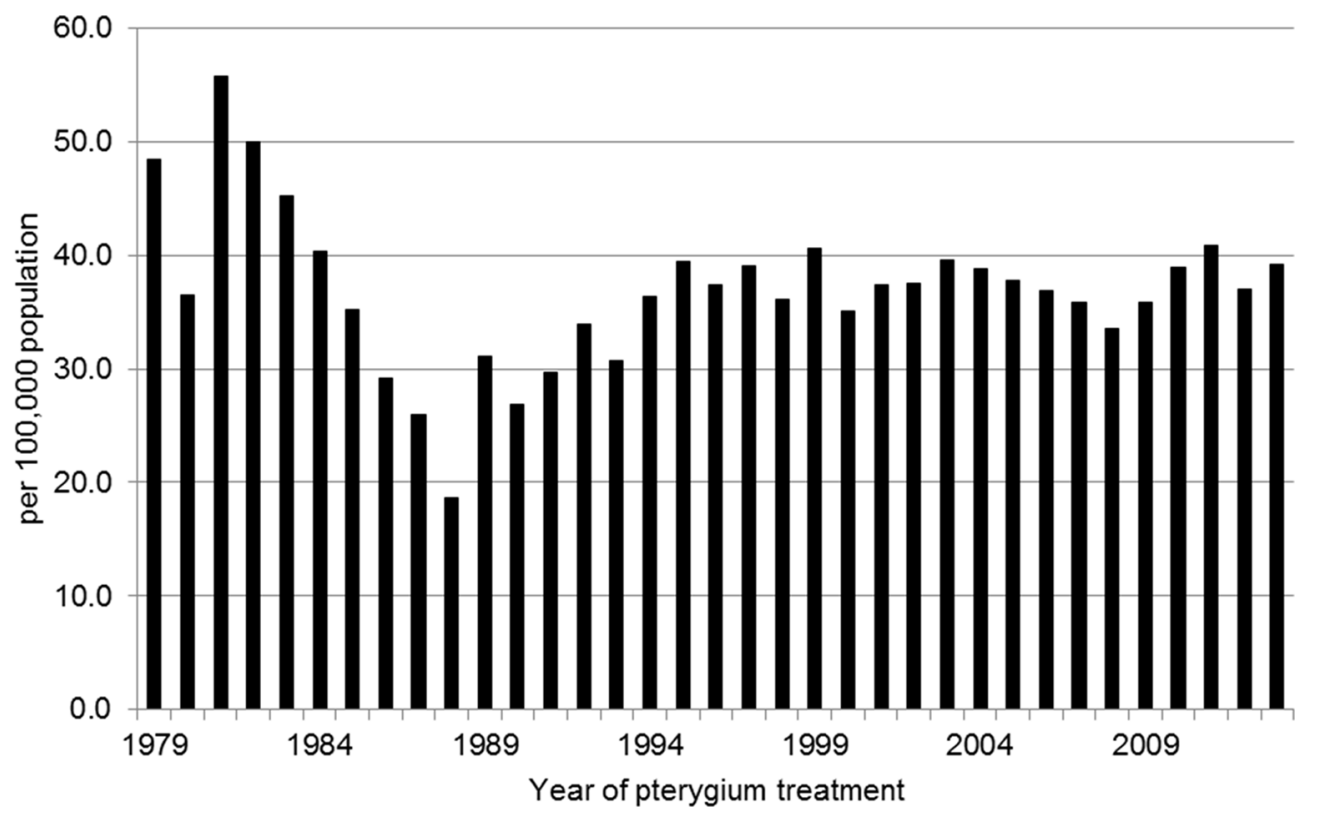

Figure 2 Incidence of hospital treated pterygium over 35 years.

relatively stable at approximately $0.04 \%$ or 39 per 100000 annually. Most recently, in 2013, there were 1001 cases of pterygium treated in WA hospitals (figure 2).

The median age at the time of pterygium treatment was 49 years (range 14-96) (figure 3). The rate of pterygium surgery in young people (aged $<25$ years) has declined from 111 per year in 1979 to approximately 30 per year (2010-2014) and the mean age of pterygium treatment has correspondingly increased from 43 years in 1979 to 56 years in 2013.

The majority $(74 \%)$ of pterygium cases were seen in people born in Australia, and this was significantly higher $(3.9, \mathrm{p}<0.001$, $95 \%$ CI 3.3 to 4.5 ) than would be expected in the 2011 WA population $\left(70 \%\right.$ born in Australia) ${ }^{17}$ (table 2). Similarly, there were proportionally more pterygium cases in people born in North Africa, the Middle East and Oceania than expected. There were fewer pterygium cases in people born in Europe, Asia, sub-Saharan Africa and North and South America.

There were 1957 CM cases diagnosed between 1982 and 2014 across both controls and pterygium cohorts (1176 MM, 781 in situ). A McNemar test of the matched pairs showed that the proportions with and without $\mathrm{CM}$ were significantly different, $\mathrm{p}<0.001$ table 3 .

Males were most commonly affected (72\% of all CMs). There were significantly more $\left(\chi^{2} p=0.001\right)$ CMs in patients with pterygium (646 MM, 437 in situ) compared with the controls (530 MM, 344 in situ) (table 1).

People resident in rural and remote locations (excluding the northern, tropical regions of WA) had the greatest prevalence of MM (pterygium 3\%, controls 2.7\%) and in situ CMs (pterygium 2.2\% and controls 1.4\%). Most MMs (66\%) were diagnosed

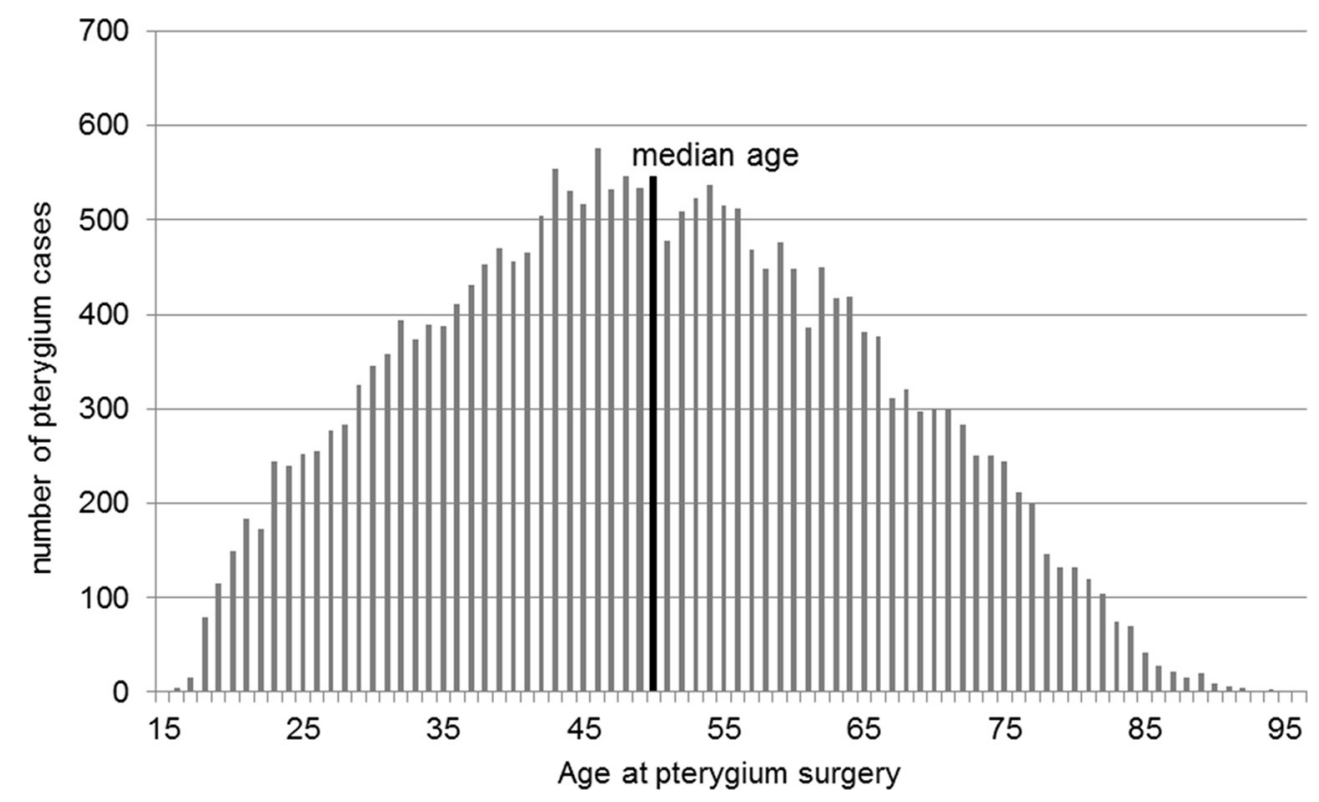

Figure 3 Age at pterygium treatment. 
Table 2 Country/region of birth of patients treated for pterygyium in Western Australia (WA) compared with the State distribution. Bolded regions show groups with higher than expected reprentations in the pterygium cohort

\begin{tabular}{|c|c|c|c|c|c|c|c|}
\hline Geographic region & $\begin{array}{l}\text { Pterygium } \\
\text { cases }\end{array}$ & $\%$ & WA pop. & $\%$ & $\mathbf{p}$ & $95 \% \mathrm{Cl}$ & \\
\hline Australia and New Zealand & 17460 & 73.9 & 1647880 & 70.0 & $<0.001$ & 3.3 & 4.5 \\
\hline Northern European & 2438 & 10.3 & 310820 & 13.2 & $<0.001$ & 2.5 & 3.3 \\
\hline Southern European & 598 & 2.5 & 66050 & 2.8 & 0.001 & 0.1 & 0.5 \\
\hline Southeast Asia & 636 & 2.7 & 110520 & 4.7 & $<0.001$ & 1.8 & 2.2 \\
\hline Northeast Asia & 136 & 0.6 & 37680 & 1.6 & $<0.001$ & 0.9 & 1.1 \\
\hline South and Central Asia & 144 & 0.6 & 52050 & 2.2 & $<0.001$ & 1.5 & 1.7 \\
\hline North Africa or Middle Eastern & 454 & 1.9 & 21870 & 0.9 & $<0.001$ & 0.8 & 1.2 \\
\hline Sub-Saharan Africa & 444 & 1.9 & 74830 & 3.2 & $<0.001$ & 1.1 & 1.5 \\
\hline Oceania (excluding Australia/New Zealand) & 209 & 0.9 & 4670 & 0.2 & $<0.001$ & 0.6 & 0.8 \\
\hline Americas & 146 & 0.6 & 27110 & 1.2 & $<0.001$ & 0.5 & 0.7 \\
\hline Unknown/missing & 960 & 4.1 & 70 & 0.0 & & & \\
\hline Total & 23625 & & 2353480 & & & & \\
\hline
\end{tabular}

after the index date of the pterygium treatment, in cases and controls.

Logistic regression analysis showed that for people who had had pterygium treatment there was a $24 \%$ increase in the odds of having a CM diagnosis after controlling for sex, age at pterygium treatment and residential postcode. Additionally, for every year increase in age at the time of the pterygium treatment, there was a $2 \%$ increase in the odds of developing a CM, after controlling for other predictors (OR 1.02, p<0.001). Overall, women were $28 \%$ less likely than men to have a CM diagnosis (OR 0.72 , $\mathrm{p}<0.001$ ) (table 4).

The unadjusted incident rate for all CMs in the pterygium cases was 3.2 per $1000 \mathrm{PY}, 1.2$ times greater (95\% CI 1.0 to 1.4) than in the control cohort 2.6 per 1000 PY. People resident in tropical latitudes $\left(15^{\circ} \mathrm{S}-23.5^{\circ} \mathrm{S}\right)$ had the highest IRR for MM (2.9, 95\% CI 2.6 to 3.2$)$ pterygium cohort to controls (1.3 vs $0.4 \mathrm{MM}$ per $1000 \mathrm{PY}$ ) (table 5).

Although there were significantly more deaths from all causes in the control cohort (4269) than in the pterygium cohort (3653, $\mathrm{p}<0.001$ ), there was no significant difference in the number of deaths in people with $\mathrm{MM}$ (pterygium $\mathrm{n}=159$, controls $n=141$; $\mathrm{p}=0.24$ ) or in people with any CM (pterygium $\mathrm{n}=227$, controls $\mathrm{n}=176 ; \mathrm{p}=0.35$ ). Malignant $\mathrm{CM}$ as the primary cause of death was reported in less than $1 \%$ of both the pterygium and control cohorts deaths $(n=34$ and 27, respectively, $p=0.09$ ).

\section{DISCUSSION}

These data show that in WA there is an increase in the odds of being diagnosed with either a MM or an in situ CM in people who have been treated for a pterygium. This novel marker of at-risk individuals is evident many years before the development of CM. Early detection of CMs can save lives. Health professionals who see patients with developing pterygium are well placed to alert these patients to this increased risk of developing

Table 3 McNemar test to compare the CM status of age-matched, sex-matched and postcode-matched pairs

\begin{tabular}{|c|c|c|c|c|}
\hline & Controls & & & McNemar \\
\hline $\begin{array}{l}\text { Pterygium } \\
\text { cases }\end{array}$ & With CM (n (\%)) & No CM (n (\%)) & Total & $\mathrm{p}$ \\
\hline With CM & $53(0.2)$ & $1030(4.4)$ & 1083 & \\
\hline No CM & 821 (3.5) & 21721 (91.9) & 22542 & \\
\hline Total & 874 & 22751 & 23625 & $<0.000$ \\
\hline
\end{tabular}

CM, cutaneous melanoma.

Crewe JM, et al. Br J Ophthalmol 2018;102:496-501. doi:10.1136/bjophthalmol-2017-310686
$\mathrm{CM}$, to recommend lifestyle changes and to promote regular skin surveillance.

Interpreting the impact of racial differences on pterygium development is complex. The WA population is predominantly Caucasian of European heritage and 15\% multicultural. No specific data on race is collected by the Australian Bureau of Statistics, hospitals or the Electoral Rolls, other than that which relates to Indigenous Australians. A recent study carried out in rural WA found that $85.5 \%$ of participants were Caucasian. ${ }^{18}$ Recent migrants to Australia are generally young adults and their susceptibility to UVR-related pathologies will vary with their racial origin and past UVR exposure. Individuals in this study cohort who were born in North Africa or in Polynesia were over-represented in the pterygium cohort, suggesting a high rate of UVR exposure in childhood and/or occupationally before or after arrival in Australia. Asian-born Australians had a lower prevalence of pterygium. Comparative studies of different racial groups have also shown variations in the prevalence of pterygium, with the highest rate (31\%) in a Japanese cohort. ${ }^{19} 20$ Together these findings suggest that skin pigmentation is not protective against pterygium development and that UVR exposure, particularly as a child, is a more critical risk factor for pterygium development.

To the best of our knowledge, there has only been one other study that has reported an increased risk of developing CM with pterygium prevalence rates. ${ }^{21} \mathrm{Yu}$ et al examined a random sample of 1 million Taiwanese for pterygium diagnoses or treatment. They

Table 4 Logistic regression analysis. OR for the risk of developing CM (MM or in situ)

\begin{tabular}{|c|c|c|c|}
\hline & OR & $95 \% \mathrm{Cl}$ & p Value \\
\hline \multicolumn{4}{|l|}{ Sex } \\
\hline Male & 1 & Ref & \\
\hline Female & 0.72 & 0.6 to 0.8 & $<0.001$ \\
\hline \multicolumn{4}{|c|}{ Age at index date (pterygium treated) } \\
\hline$<50$ years & 1 & Ref & \\
\hline$\geq 50$ years & 1.02 & 1.0 to 1.0 & $<0.001$ \\
\hline \multicolumn{4}{|l|}{ Resident } \\
\hline Urban & 1 & Ref & \\
\hline Rural/tropical & 1.05 & 0.9 to 1.1 & 0.31 \\
\hline \multicolumn{4}{|l|}{ Pterygium } \\
\hline No & 1 & Ref & \\
\hline Yes & 1.24 & 1.1 to 1.4 & $<0.001$ \\
\hline
\end{tabular}


Table 5 Crude incidence rate ratio (IRR) of malignant cutaneous melanomas in pterygium and control cohorts

\begin{tabular}{|c|c|c|c|c|c|c|c|}
\hline & \multicolumn{3}{|c|}{ Pterygium } & \multicolumn{3}{|l|}{ Controls } & \multirow[b]{2}{*}{ IRR $(95 \%$ Cl) } \\
\hline & Number & PY & Rate* & Number & PY & Rate* & \\
\hline All & 646 & 346371 & 186.5 & 530 & 333847 & 158.8 & $1.2(1.0$ to 1.4$)$ \\
\hline \multicolumn{8}{|l|}{ Sex } \\
\hline Male & 466 & 220395 & 211.4 & 388 & 212653 & 182.5 & $1.2(1.0$ to 1.4$)$ \\
\hline Female & 180 & 125976 & 142.9 & 142 & 121194 & 117.2 & $1.2(1.0$ to 1.5$)$ \\
\hline \multicolumn{8}{|l|}{ Age group } \\
\hline$<50$ years & 228 & 209021 & 109.1 & 184 & 205320 & 89.6 & 1.2 (0.9 to 1.5$)$ \\
\hline$>49$ years & 418 & 137350 & 304.3 & 346 & 128527 & 269.2 & 1.1 (1.0 to 1.3$)$ \\
\hline \multicolumn{8}{|c|}{ Residential postcode } \\
\hline Metropolitan & 437 & 237943 & 183.7 & 351 & 225103 & 155.9 & $1.2(1.0$ to 1.4$)$ \\
\hline Regional & 192 & 95240 & 201.6 & 173 & 95316 & 181.5 & 1.1 (0.9 to 1.3$)$ \\
\hline Tropical & 17 & 13188 & 128.9 & 6 & 13428 & 44.7 & 2.9 (2.5 to 3.2$)$ \\
\hline
\end{tabular}

*Per 100000 PY.

PY, total person-years in the study.

identified 19701 pterygium cases (2\% of the cohort population) over the most recent 14 years. Of those, only seven $(0.04 \%)$ individuals had a MM diagnosis. These data reflect the lower prevalence of CMs in Asian populations despite being resident in lower latitudes (Taiwan $23.7^{\circ} \mathrm{N}$ ) with higher levels of UVR..$^{22} 23$ By contrast, in the largely Caucasian population of WA (latitude $\left.15^{\circ} \mathrm{S}-35^{\circ} \mathrm{S}\right)$, the risk of developing a CM is 85 times greater than that reported in the Taiwanese cohort. We identified a total of 1083 CMs (MM and in situ) diagnosed over a 32-year period in the cohort of people who had also had pterygium treatment.

The IRR for this study cohort, over 32 years, was lower (1.2, $95 \%$ CI 1.0 to 1.4$)$ than that in the Taiwanese study, over 14 years $(1.7,95 \%$ CI 1.6 to 1.8$)$. The IRR reflects the number of cases of $\mathrm{MM}$ in the pterygium and control groups as a ratio of one to the other, but it does not provide information on the overall number of individuals developing MM. So although we found a hundred times as many individuals developing MM $(4.6 \%)$ in the pterygium cases $(1,083)$, the Taiwanese study had $0.04 \% \mathrm{MM}$ cases in their pterygium group. The higher IRR of 1.7 in the Taiwanese study reflects a higher ratio of $\mathrm{MM}$ in the pterygium cases $(n=7)$ compared with their control group $(n=16)$ but as their total number of MM cases was very small, a single additional case in the pterygium group would result in a significant increase in the ratio. We did extract a subset of data from our 35-year dataset, for the same time period as the Taiwanese study (1997-2010), for comparison and found a consistent IRR $(1.2,95 \%$ CI 1.1 to 1.3$)$ as that over the total 35 years. It would be interesting to follow the Taiwanese cohort over the next 15-20 years.

This study benefited from the availability of whole population linked health data sets within the Western Australian state health and social service sector, that is representative of the wider Australian population. ${ }^{24}$ Data can be linked between different registries at the individual person level throughout the entire state population and so avoids bias of single treatment centres or individual clinicians. A weakness of this study is that only a small proportion of pterygium cases will receive in-hospital treatment, and therefore this study cohort is not fully representative of all individuals with pterygium.

Nevertheless, the vast majority of pterygium surgery in WA is performed in hospital facilities across the study period and would be captured. Most pterygium will remain untreated for many years after they become clinically obvious. Despite this, in this study cohort of more than 23000 cases, most CMs (66\%) were diagnosed after the date of the pterygium treatment.
Other factors are known to increase the risk of CM development. Mutations in the retinoblastoma gene, a tumour suppressor gene causing childhood retinoblastoma, also increases the risk of developing CMs. ${ }^{25}$ Although other countries have reported a strong racial component to the incidence and prevalence of $\mathrm{CM}$ in Caucasians compared with African American or Hispanic populations, in Australia data on 'race' are limited to Indigenous Australians or Others. The current population in WA is predominantly (>90\%) Caucasian, of European origin. Country of birth is routinely recorded on hospital admissions and so all pterygium cases derived from hospital records were grouped by global region of birth, as a proxy for racial groupings. The same information was not available for the control cohort derived from the State Electoral Roll. However, as voting is compulsory in Australia, the State Electoral Rolls are fully representative of the adult population and are commonly used as a source of control populations in epidemiology studies.

Epidemiological studies have indicated that solar UVR plays a major role in the pathogenesis of pterygia, ${ }^{527}$ first reported by Talbot in $1948^{28}$ and continues to be reported in the Australia population $^{29} 30$

It is now also well established that solar UVR is a causative agent in the initiation and progression of melanomas (squamous cell, basal cell carcinomas and CMs). ${ }^{15}$ Specifically, UVR has been proven to be a highly toxic and a mutagenic agent inducing damage to cellular DNA. ${ }^{31}$ However, there is also evidence that the relationship between UVR and CM is not a simple dose-related effect. Studies in Australia have shown that people who regularly work outside and receive relatively high UVR exposure do not have increased rates of CMs compared with those working mainly indoors. ${ }^{32}$ There may be a positive case for moderate UVR exposure linked to sun-induced vitamin D levels, suggesting a beneficial role for maintaining some level of regular UVR exposure. ${ }^{28}$ Recent research has found that increased time outdoors may also be protective against developing myopia (short sightedness) and that people with self-reported skin cancers (high UVR exposures) are less likely to be myopic. ${ }^{33}$

In this study, there were significantly fewer deaths from all causes in the pterygium cases compared with controls, which suggests a positive health benefit is conferred in those who have pterygium and an assumed higher UVR exposure. However, this possible association requires further study. Continued vigilance and further studies are required in Australia to better understand and define safe UVR exposure limits that balance the maintenance of adequate vitamin D levels and immune surveillance 
systems, while minimising the incidence and mortality of CMs. This is a complex but important healthcare message to promote, to convey and to evaluate. ${ }^{34} 35$

Early diagnosis has been key to improving CM survival rates in recent years. ${ }^{2}$ There have been few treatment options that have improved overall survival in patients with advanced CM beyond 6 months and only a quarter of patients alive at 1 year regardless of treatment regimen. However, the advent of new immunotherapies targeting immune-checkpoint inhibitors (serine/threonine-protein kinase B-Raf) are offering the prospect of sustained remission in selected patients, and again these treatments work better when started early rather than in patients who have progressed.

Contributors Professor DAM was responsible for the original concept for this research. All authors contributed to the planning, analyses, reporting and final oversight of this manuscript. JMC affirms that the manuscript is an honest, accurate and transparent account of the study being reported and that no important aspects of the study have been omitted.

Funding This study was funded by private donations to the Lions Eye Institute. The sponsors had no role in the design or conduct of this research.

Competing interests None declared.

Patient consent This study was exempt from obtaining consent from individuals by the ethics committee. The study uses health service data on more than 45000 individuals.

Ethics approval University of Western Australia and the Department of Health of Western Australia

Provenance and peer review Not commissioned; externally peer reviewed.

Data sharing statement No data currently available due to confidentiality restrictions.

(c) Article author(s) (or their employer(s) unless otherwise stated in the text of the article) 2018. All rights reserved. No commercial use is permitted unless otherwise expressly granted.

\section{REFERENCES}

1 Thompson JF, Scolyer RA, Kefford RF, et al. Cutaneous melanoma. Lancet;365:687-70.

2 Beddingfield FC. The melanoma epidemic: res ipsa loquitur. Oncologist 2003;8:459-65

3 Taylor HR, West SK, Rosenthal FS, et al. Corneal changes associated with chronic UV irradiation. Arch Ophthalmol 1989;107:1481-4.

4 Moran DJ, Hollows FC. Pterygium and ultraviolet radiation: a positive correlation. $\mathrm{Br} J$ Ophthalmol 1984;68:343-6.

5 Coroneo MT. Pterygium as an early Indicator of ultraviolet insolation: a hypothesis. $\mathrm{Br}$ J Ophthalmol 1993;77:734-9.

6 Khoo J, Saw SM, Banerjee K, et al. Outdoor work and the risk of Pterygia: a casecontrol study. Int Ophthalmol 1998;22:293-8.

7 Mackenzie FD, Hirst LW, Battistutta D, et al. Risk analysis in the development of pterygia. Ophthalmology 1992;99:1056-61.

8 Taylor HR. The prevalence of corneal disease and cataracts in australian aborigines in Northwestern Australia. Aust J Ophthalmol 1980;8:289-301.

9 Watts CG, Cust AE, Menzies SW, et al. Cost-effectiveness of skin surveillance through a specialized clinic for patients at high risk of melanoma. J Clin Oncol 2017:35:63-71
10 Ernst DS, Petrella T, Joshua AM, et al. Burden of illness for metastatic melanoma in Canada, 2011-2013. Curr Oncol 2016:23:563-e70.

11 Green AC, Baade P, Coory M, et al. Population-based 20-year survival among people diagnosed with thin melanomas in Queensland, Australia. J Clin Oncol 2012;30:1462-7

12 Coory M, Baade P, Aitken J, et al. Trends for in situ and invasive melanoma in Queensland, Australia, 1982-2002. Cancer Causes Control 2006;17:21-7.

13 Whiteman DC, Green AC, Olsen CM, et al. The growing burden of invasive melanoma: projections of Incidence rates and numbers of new cases in six susceptible populations through 2031. J Invest Dermatol 2016;136:1161-71.

14 Ribero SG, Bataille DV. Genetic epidemiology of melanoma. Eur J Dermatol 2016:26:335-9.

15 IARC. Monograph: solar and U/traviolet Radiation. International Agency for Research on Cancer, 2012.

16 Carey RN, Glass DC, Peters S, et al. Occupational exposure to solar radiation in Australia: who is exposed and what protection do they use? Aust N Z J Public Health 2014;38:54-9.

17 Australian Bureau of Statistics. http://www.abs.gov.au/Population2011.

18 McKnight CM, Sherwin JC, Yazar S, et al. Myopia in young adults is inversely related to an objective marker of ocular sun exposure: the Western Australian Raine cohort study. Am J Ophthalmol 2014;158:1079-85.

19 Shiroma H, Higa A, Sawaguchi S, et al. Prevalence and risk factors of pterygium in a southwestern island of Japan: the Kumejima Study. Am J Ophthalmol 2009;148:766-71.

20 Ang $M$, Li X, Wong W, et al. Prevalence of and racial differences in pterygium: a multiethnic population study in Asians. Ophthalmology 2012;119:1509-15.

$21 \mathrm{Yu} \mathrm{HC}$, Lin CL, Chen ZT, et al. Risk of skin cancer in patients with pterygium: a nationwide population-based cohort study in Taiwan. Ocul Surf 2014;12:69-76.

22 Kim SY, Yun SJ. Cutaneous melanoma in Asians. Chonnam Med J 2016;52:185-93.

23 Eide MJ, Weinstock MA. Association of UV index, latitude, and melanoma incidence in nonwhite populations--US Surveillance, Epidemiology, and End results (SEER) Program, 1992 to 2001. Arch Dermatol 2005;141:477-81.

24 Clark A, Preen DB, Ng JQ, et al. Is Western Australia representative of other Australian States and Territories in terms of key socio-demographic and health economic indicators? Aust Health Rev 2010;34:210-5.

25 Marees $\mathrm{T}$, van Leeuwen $\mathrm{FE}$, de Boer MR, et al. Cancer mortality in long-term survivors of retinoblastoma. Eur J Cancer 2009:45:3245-53.

26 Temming $\mathrm{P}$, Arendt M, Viehmann A, et al. How eye-preserving therapy affects long-term overall survival in heritable retinoblastoma survivors. J Clin Oncol 2016;34:3183-8

27 Threlfall TJ, English DR. Sun exposure and pterygium of the eye: a dose-response curve. Am J Ophthalmol 1999;128:280-7.

28 Talbot G. Pterygium. TransOphthalmo/ Soc NZ 1948;2:42-5.

29 McKnight CM, Sherwin JC, Yazar S, et al. Pterygium and conjunctival ultraviolet autofluorescence in young Australian adults: the Raine study. Clin Exp Ophthalmol 2015:43:300-7.

30 Landers J, Henderson T, Craig J, et al. Prevalence of pterygium in indigenous Australians within central Australia: the Central Australian Ocular Health Study. Clin Exp Ophthalmol 2011;39:604-6.

31 Lucas R, McMichael T, Smith W, et al. Solar ultraviolet radiation: global burden of disease from solar ultraviolet radiation. Geneva, Switzerland: World Health Organization, 2006.

32 Vuong K, McGeechan K, Armstrong BK, et al. Occupational sun exposure and risk of melanoma according to anatomical site. Int J Cancer 2014;134:2735-41.

33 Moan J, Porojnicu AC, Dahlback A, et al. Addressing the health benefits and risks, involving vitamin D or skin cancer, of increased sun exposure. Proc Natl Acad Sci U SA 2008:105:668-73.

34 Franchina M, Yazar S, Hunter M, et al. Myopia and skin cancer are inversely correlated: results of the Busselton Healthy Ageing Study. Med J Aust 2014:200:521-2.

35 Hoel DG, Berwick M, de Gruijl FR, et al. The risks and benefits of sun exposure 2016. Dermatoendocrinol 2016:8:e1248325. 